\title{
Left Ventricular Hypertrophy: a Comparison Among Kurdish Patients with First-ever Ischemic Versus First-ever Hemorrhagic Stroke
}

\author{
Osama Shukir Muhammed Amin \\ Department of neurology, Sulaimaniya general teaching hospital, Sulaimaniya city, Iraq
}

D ackground and Aim: Left ventricular hypertrophy $(\mathrm{LVH})$ has been proposed to be associated with an increased risk of stroke. We compared the prevalence of LVH among patients with first-ever ischemic versus first-ever hemorrhagic strokes. Material and methods: This observational study, which was conducted at the Sulaimaniya general teaching hospital from November 2009 to March 2012, involved 100 consecutive patients with their first-ever stroke. Fifty patients had ischemic stroke while the rest $(n=50)$ developed hemorrhagic stroke. The presence of LVH was detected using transthoracic echocardiography and a comparison with respect to its prevalence between the 2 aforementioned groups was made. Results: The mean age of patients in the hemorrhagic group was $61.7 \pm \mathrm{SD} 11.2$ years while in the ischemic group it was $63.9 \pm \mathrm{SD} 6.1$ years. Out of 100 patients, 66 (66\%) patients were males (31 in the hemorrhagic group and 35 in the ischemic group) while the rest ( $\mathrm{n}=34 ; 34 \%)$ were females (19 in the hemorrhagic group and 15 in the ischemic one). Ninety one (91\%) patients were hypertensive (47 in the hemorrhagic group and 34 in the ischemic group). Fifty three (53\%) out of 100 patients demonstrated LVH (31 in the hemorrhagic group and 22 in the ischemic group). A head-to-head comparison between the two groups with respect to gender demonstrated no statistically significant difference in terms of the presence of LVH among patients with hemorrhagic versus ischemic strokes; males (P value $<0.26$; 95\% CI 3.4-39.3); females (P value $<0.43$; 95\% CI 16.7-43.8). However, a univariate analysis after correction for age and gender revealed a statistically significant difference between these groups (P-value $<0.001$; 95\% CI 2.7-46.2). Conclusion: LVH was more common in Kurdish patients with first-ever hemorrhagic stroke than in those who had sustained their first-ever ischemic stroke. Further analytic studies are required to clarify the prevalence of LVH in patients with ischemic stroke. Key words: left ventricular hypertrophy; stroke; myocardial mass index

Corresponding author: Osama Shukir Muhammed Amin MD, MRCPI, MRCPS(Glasg), FCCP, FACP. Sulaimaniya post-office, PO BOX 196. Sulaimaniya city, Iraq. Mobile: 0096477043515964 . E-mail: dr.osama.amin@gmail.com

\section{INTRODUCTION}

Left ventricular hypertrophy is an overall increase in the left ventricular myocardial mass as a result of chronically elevated afterload (e.g., hypertension and aortic stenosis). It also may result from a longstanding elevation in the diastolic filling, as in chronic aortic and mitral regurgitation. Coronary artery disease has been found to result in
$\mathrm{LVH}$; the myocardium pumps more in an attempt to compensate for the ischemic/infarcted area(s). Genetic factors also may play a role. Myocardial fibrosis is the key component in the development of LVH; this initially results in diastolic dysfunction and finally systolic failure may ensue. A chronically stimulated and active renin-angiotensin-aldosterone system has been linked pathophysiologically to this fibrotic process. More specifically, angiotensin II exerts a profibrotic effect on the heart of hypertensive patients and this explains why angiotensin-converting enzyme inhibitors or angiotensin receptor blockers are potent agent against LVH.[1-7]

\section{MATERIALS AND METHODS}

This observational study was conducted at the department of neurology of Sulaimaniya general teaching hospital, Iraq, from November 2009 to March 2012. One hundred patients who had developed their first-ever stroke were enrolled. Patients have been divided into 2 groups; 50 in the ischemic group and 50 in the hemorrhagic one.

To be eligible for enrollment in the study, patients must have developed their first ever stroke (defined clinically as neurological deficit or deficits that had persisted for more than 24 hours). The presence of a past history of stroke (hemorrhagic or ischemic, including transient ischemic attacks; clinically or imaging wise); valvular heart disease (stenotic or regurgitant); congenital heart disease (corrected or not); prior coronary intervention; and congestive heart failure were excluded patients from the study. All patients were Kurdish (an ethnic minority in the northern Iraqi area) and residents of Sulaimaniya city. 
All patients $(n=100)$ were examined by a single neurologist and neurology trainees and they underwent routine blood testing, 12-lead resting ECG, transthoracic echocardiography, and CT brain scanning within 48 hours of their hospital admission.

Echocardiographic testing was done using a Philips machine, Envisor-HD operating on software of Philips version C.1.3, 2007 and a probe of S4-2. This testing was performed by a single operator. The septal thickness (at enddiastole), left ventricular posterior free wall (at end-diastole), and end-diastolic interior diameter of the left ventricle were measured on the M-mode. Using these measurements, together with the patients' weight and height, we calculated the left ventricular mass index (LVMI) through ordinary electronic calculators, using this equation:

L V M I $\quad\left(\mathrm{g} / \mathrm{m}^{2}\right)=\left(\begin{array}{lll}1.0 & 4\end{array}\right.$ $\left.\left[\left(\mathrm{IVST}^{2} \mathrm{LVID}+\mathrm{PWT}\right)^{3}-\mathrm{LVID}^{3}\right]-14 \mathrm{~g}\right) /$ Body surface area.

The presence of LVH was defined if the LVMI (expressed as $\mathrm{g} / \mathrm{m}^{2}$ ) was greater than $134 \mathrm{~g} / \mathrm{m}^{2}$ in men and more than $110 \mathrm{~g} / \mathrm{m}^{2}$ in women. A comparison of this LVMI between the ischemic and hemorrhagic group was done.

The collected data was organized, tabulated, and statistically analyzed using Statistical Package for Social Sciences (SPSS) version 17 by an independent statistician. Values were expressed as mean $\pm \mathrm{SD}$ (standard deviation). A comparison of continuous variables was performed by an unpaired two-tailed Student's t-test, whilst chi-square tests were used for categorical variables. Significance levels were set at $P$-value of less than 0.05 in all cases.

\section{RESULTS}

Table 1 compares the associations among the various patients' vascular risk factors while tables 2-4 demonstrate the distribution of $\mathrm{LVH}$ and LVMI among our patients and their statistical comparison.

The mean age of the patients in the hemorrhagic group was $61.7 \pm$ SD 11.2 years while in the ischemic group it was $63.9 \pm$ SD 6.1 years. Overall and out of our 100 patients, 66 patients were males (31 in the hemorrhagic group and 35 in the ischemic group) while the rest (34)

were females (19 in the hemorrhagic and 15 in the ischemic group). Ninety one patients were hypertensive (47 in the hemorrhagic group and 34 in the ischemic group).

Fifty three (53\%) out of 100 patients demonstrated an increased LVMI and LVH (31 in the hemorrhagic group and 22 in the ischemic group). A head-to-head comparison between the two groups with respect to gender demonstrated no statistically significant difference in terms of the presence of $\mathrm{LVH}$ among patients with hemorrhagic versus ischemic strokes; males ( $\mathrm{P}$ value $<0.26$; 95\%CI 3.4-39.3); females (Pvalue $<0.43$; 95\% CI 16.7-43.8). However, a univariate analysis after correction for age and gender revealed a statistically significant difference between these groups ( $\mathrm{P}$ value $<0.001 ; 95 \%$ CI 2.7-46.2). Among all risk factors for

\begin{tabular}{|l|l|l|l|}
\hline \multirow{2}{*}{ Character } & & Number & $\begin{array}{l}\text { Percentage per } \\
\text { gender of the } \\
\text { pertinent group }\end{array}$ \\
\hline \multirow{2}{*}{ Males $^{\star}$} & Hemorrhagic & 20 & $64 \%$ \\
\cline { 2 - 4 } & Ischemic & 15 & $42 \%$ \\
\hline \multirow{2}{*}{ Females $^{* *}$} & Hemorrhagic & 11 & $52 \%$ \\
\cline { 2 - 4 } & Ischemic & 7 & $46 \%$ \\
\hline
\end{tabular}

Table 2. The distribution of LVH among patients with hemorrhagic $(n=50)$ versus ischemic $(n=50)$ stroke. ${ }^{*} \mathrm{LVMI}$ $>134 \mathrm{~g} / \mathrm{m} 2$ in men defines $\mathrm{LVH} .{ }^{* \star} \mathrm{LVMl}>110 \mathrm{~g} / \mathrm{m} 2$ in women defines LVH.

stroke development in both groups, a history of ischemic heart disease was more common in the ischemic group ( $P$ value $<0.003$ )

ventricle (as in chronic aortic and mitral refluxes) and coronary artery disease may also incur a stress on the myocardium to increase its volume. More than one factor may be operative and

\begin{tabular}{|c|c|c|c|c|c|c|c|}
\hline \multirow{2}{*}{ Character } & & \multirow{2}{*}{ Mean } & \multirow{2}{*}{$\begin{array}{l}\text { Standard } \\
\text { Deviation }\end{array}$} & \multirow{2}{*}{$\begin{array}{l}\text { Mean } \\
\text { difference }\end{array}$} & \multirow{2}{*}{$P$ value } & \multicolumn{2}{|c|}{$\begin{array}{l}95 \% \text { Confidence } \\
\text { interval }\end{array}$} \\
\hline & & & & & & Lower & upper \\
\hline \multirow{2}{*}{ LVMI, Males } & Hemorrhagic & 183.7 & 51.1 & \multirow{2}{*}{16} & \multirow{2}{*}{$0.26^{\star}$} & \multirow{2}{*}{-3.4} & \multirow{2}{*}{39.3} \\
\hline & Ischemic & 174.2 & 39.2 & & & & \\
\hline \multirow{2}{*}{$\begin{array}{l}\text { LVMI, } \\
\text { Females }\end{array}$} & Hemorrhagic & 191.6 & 47.8 & \multirow{2}{*}{17.7} & \multirow{2}{*}{$0.43^{*}$} & \multirow{2}{*}{-16.7} & \multirow{2}{*}{43.8} \\
\hline & Ischemic & 169.3 & 53.4 & & & & \\
\hline
\end{tabular}

Table 3. Mean LVMI in the hemorrhagic stroke group $(n=50)$ and the ischemic stroke one $(n=50)$ with respect to gender. * Not significant.

\begin{tabular}{|l|l|l|l|l|l|l|l|}
\hline \multirow{2}{*}{ Character } & & Mean & $\begin{array}{l}\text { Standard } \\
\text { Deviation }\end{array}$ & $\begin{array}{l}\text { Mean } \\
\text { difference }\end{array}$ & P value & \multicolumn{3}{|l|}{$\begin{array}{l}\text { 95\% Confidence } \\
\text { interval }\end{array}$} \\
\cline { 3 - 8 } & & & & Lower & upper \\
\cline { 2 - 7 } & Hemorrhagic & 187.6 & 48.3 & 16.4 & $0.001^{*}$ & -2.7 & 46.2 \\
\hline
\end{tabular}

Table 4. A comparison of the mean LVMI of the hemorrhagic stroke group $(n=50)$ with the ischemic stroke one $(n=50)$.

\section{DISCUSSION}

Left ventricular hypertrophy (LVH) reflects an overall increment in the mass of the left ventricle. This is a compensatory mechanism adopted by the myocardium in response to various stresses on the heart. A rise in the afterload (e.g., longstanding systemic hypertension or aortic stenosis) is by far the commonest cause. An increase in the volume (diastolic) load on the left altogether they can augment this volume increment.[1-3]

Genetic factors play a role, in addition, in the pathogenesis of LVH. For instance, certain mutations in the myocardial sarcomeric proteins result in various types of hypertrophic cardiomyopathy.[4] Furthermore, Liebson and coworkers found that some people with mild hypertension develop LVH while others don't and he suggested that cer- 
tain genes might have played a role in this process.[5]

Myocardial fibrosis is the key component in the development of LVH; this initially results in diastolic dysfunction and finally systolic failure may ensue. A chronically stimulated and active renin-angiotensin-aldosterone system has been linked pathophysiologically to this fibrotic process. More specifically, angiotensin II exerts a profibrotic effect on the heart of hypertensive patients and this explains why angiotensin converting enzyme inhibitors or angiotensin receptor blockers are potent agents agent against LVH.[4,6,7]

Several investigators have found that LVH is a risk factor for cardiovascular events and it portends 7-fold increment in this risk among the general population and especially hypertensive ones.[8,9] On the other hand, Bikkina et al[10] and Aronow et al[11] reported an association between LVH and stroke but the link has been questioned by researchers.[12] However, Bahemuka[13] found that the weight of the heart was generally grater in patients with hypertensive intracerebral hemorrhage ( $\mathrm{ICH})$ than in patients who had not sustained ICH. Okin and colleagues[14] concluded that the diameter of the carotid artery correlates well with the mass of the left ventricle.

In our study, in terms of prevalence of LVH and increased LVMI, there was no statistically significant difference among patients with first-ever ischemic versus hemorrhagic stroke, when both genders are compared headhead, although LVH was found more commonly in hemorrhagic stroke patients (31 patients) than in patients with ischemic stroke (22 patients). This might be explained by the fact longterm hypertension is a risk factor for stroke, whether ischemic or hemorrhagic, $[15,16]$ and that $\mathrm{LVH}$ is an expected aftermath of this chronically elevated systemic blood pressure.[17, 18] However, a direct comparison between the two stroke groups, adjusted for age and gender, revealed that an elevated LVMI was more common in hemorrhagic stroke patients than in patients with ischemic stroke and that this observation is statistically significant. Whether this "statistical" outcome is "clinically significant or not, it has to be confirmed or refuted by further analytic studies.

The mechanisms and links between LVH and stroke are diverse and many are still controversial. With respect to ischemic stroke: it predisposes to atrial fibrillation; [19] predicts the presence of carotid atherosclerosis (and it correlates well with carotid intimal thickness); [20] it could represent a time-integrated indicator of exposure to other vascular risk such as hypertension or morbid obesity;[21] an association with asymptomatic cerebrovascular ischemic lesions;[22] and through an association with dyslipidemia.[23]

As for the hemorrhagic stroke, it has been suggested that the presence of LVH is a mere marker of chronic hypertension and wide-spread end-organ damage, including intracerebral Charcot-Bouchard microaneurysm formation and rupture.[16,24,25]

According to Di Tullio and colleagues,[26] LVH appeared to be independently associated with stroke, regardless of the age, sex, and ethnicity of the target population, and this is consistent with our observations. However, the increased prevalence among our Kurdish hemorrhagic stroke patients needs further analysis.

\section{CONCLUSION}

LVH has been found to be more common in our Kurdish patients with first-ever hemorrhagic stroke than in those who sustained their first-ever ischemic stroke, after adjusting for age and gender. However, the link between this observation and the development of stroke itself needs to be clarified by further analytic studies.

\section{Limitations of the study}

* This is a single institutional study that does not reflect the practice of stroke in the whole of Iraq.

* The target population was composed of patients of Kurdish ethnicity only, who might well have different genetic/ cardiovascular risk factors from Arab patients (the latter constitute the majority of the Iraqi population and were not involved in the study).

* The number of patients was relatively small.
4. There was no healthy control group to compare the results with. In addition, no prior local studies were published addressing the same target.

Taking into consideration the aforementioned factors, our findings might have been different if other institutions and ethnicities were enrolled and if the number of patients was larger.

Acknowledgments

Special thanks go to our patients and their families; without their kind cooperation, this study would have not been accomplished. I'm very grateful to our neurology trainees as well as our medical and paramedical staff and our imaging departments for their kind help in conducting this study.

\section{REF
1.
2.
3.
4.
5.
6.
7.
8.
9.
10.
11.}

Lorell BH, Carabello BA. Left ventricular hypertrophy: pathogenesis, detection, and prognosis. Circulation. 2000; 102: 470-479. Burl MA, Underwood DA. Left ventricular hypertrophy: an 77(6): $381-387$.

Fabalgoitia M, Berning J, Koren MJ. et al. Impact of coronary artery disease on left ventricular systolic function and geometry in hypertensive patients with left ventricular hypertrophy (the LIFE study). Am J Cardiol. 2001; 88: 646-650.

Maron BJ. Hypertrophic cardiomyopathy: a systematic review. JAMA. 2002; 287: 1308-1320.

Liebson PR, Grandits G, Prineas R. et al. Echocardiographic correlates of left ventricular structure among 844 mildly hypertensive men and women in the Treatment of Mild Hypertension Study

(TOMHS). Circulation. 1993; 87: 476-486.
Weber KT, Janicki JS, Pick R, Capasso J, Anversa P. Myocardial fibrosis and pathologic hypertrophy in the rat with renovascula hypertension. Am J Cardiol.1990; 65: 1G-7G.

finzilez A, Lopez B, Querejeta R, DiezJ. Regulation of myocardia dicese? I Mol Cell Cardiol. 2002:34:1585-1593. disease? Mol Cell Cardiol. 2002, $34.1585-1593$.

Levy D, Garrison R,, Savage DD. et al. Prognostic implications of Frocirdiographically determined left ventricular mass in the Framingham heart study. N Engl I Med. 1990; 322: 1561-1566.
Koren MI, Devereux RB, Casale PN. et al. Relation of left ventric Koren M], Devereux RB, Casale PN. et al. Relation of left ventric-
ular mass and geometry to morbidity and mortality in uncomplicated essential hypertension. Ann Intern Med. 1991;114: 345-352 cated essential hypertension. Ann Intern Med. 1991;114: 345-352.
Aronow WS, Ahn C, Kronzon I. et al. Association of extracranial carotid arterial disease, prior atherothrombotic brain infarction, systemic hypertension, and left ventricular hypertrophy with the incidence of new atherothrombotic brain infarction at 45 -month follow-up in 1,482 older patients. Am J Cardiol. 1997; 79: 991-993. Bikkina M, Levy D, Evans JC. et al. Left ventricular mass and risk of stroke in an elderly cohort. The Framingham Heart Study. JAMA. 1994; 272: 33-36.

12. Devereux RB. Left ventricular mass and stroke: what is the con-

13. Bahemuka M. Primary intracerebral hemorrhage and heart weight a clinicopathologic case-control review of 218 patients. Stroke.

14. Okin PM, Roman MJ, Devereux RB. et al. Association of carotid atherosclerosis with electrocardiographic myocardial ischemi and left ventricular hypertrophy. Hypertension. 1996; 28: 3-7. Sacco RL, Benjamin EJ, Broderick JP. et al. American Heart Association Prevention Conference. IV. Prevention and Reha
of Stroke. Risk factors. Stroke. 1997; 28(7): 1507-1517. Woo D, Haverbusch M, Sekar P. et al. Effect of untreated hypertension on hemorrhagic stroke. Stroke. 2004; 35(7): 1703-1708. Cuspidi C, Meani S, Sala C, Valerio C, Negri F, Mancia G. Age related prevalence of severe left ventricular hypertrophy in essential hypertension: Echocardiographic findings from the ETODH study. Blood Press. 2012; 21(3): 139-145.

18. Mallion JM, Baguet JP, Siché JP, Tremel F, De Gaudemaris R. Lef ventricular hypertrophy and arterial hypertrophy. Adv Exp Med Biol. 1997; 432: 123-133

19. Varazi SM, Larson MG, Benjamin EJ, Levy D. Echocardiographic predictors of nonrheumatic atrial fibrillation: the Framinghan

20. Kronmal RA, Smith VE, O'Leary DH, Polak JF, Gardin JM, Manolio TA. Carotid artery measures are strongly associated with lef

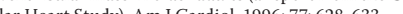
lanjer

21. Benjamin EJ, Levy D. Why is left ventricular hypertrophy so predictive of

22. Kohara K, Zhao B, Jiang Y. et al. Relation of left ventricular hypertrophy and geometry to asymptomatic cerebrovascular damage in essential hypertension. Am J Cardiol. 1999; 83: 367-370. Sundström J, Lind L, Vessby B. et al. Dyslipidemia and an unfavorable fatty acid profile predict left ventricular hypertrophy 20 years later. Circulation. 2001; 103: 836-841.

Amin OSM, Rasheed AH, Ahmed SM. Simultaneous intracerebral haemorrhages; which came first, the supra-tentoral o the infra-tentorial one? BMJ Case Reports. 2010; doi:10.1136

25. bcr.03.2010.2805. Ahmed S. Recurrent, sequential, bilateral deep cerebellar hem-

Di Stroke. 2003; 34(10): 2380-2384. 